\title{
Article \\ Measuring Community Green Inequity: A Fine-Scale Assessment of Beijing Urban Area
}

\author{
Yuyang Zhang ${ }^{1}$, Qilin $\mathrm{Wu}^{2}$, Lei $\mathrm{Wu}^{3}$ and Yan $\mathrm{Li}^{1}{ }^{1}$ * \\ 1 School of Architecture, Tsinghua University, Beijing 100084, China; yuyond@mail.tsinghua.edu.cn \\ 2 Tsinghua Urban Planning and Design Institute, Beijing 100085, China; wuqilin@thhdg.com \\ 3 Beijing Zhongcheng Youwei Technology Co., Ltd., Beijing 100085, China; wulei@sinodata.net.cn \\ * Correspondence: yanli427@hotmail.com
}

Citation: Zhang, Y.; Wu, Q.; Wu, L.; $\mathrm{Li}$, Y. Measuring Community Green Inequity: A Fine-Scale Assessment of Beijing Urban Area. Land 2021, 10, 1197. https://doi.org/10.3390/ land10111197

Academic Editors: Zhonghua Gou and Alexandru-Ionuţ Petrişor

Received: 28 September 2021

Accepted: 4 November 2021

Published: 5 November 2021

Publisher's Note: MDPI stays neutral with regard to jurisdictional claims in published maps and institutional affiliations.

Copyright: (c) 2021 by the authors. Licensee MDPI, Basel, Switzerland. This article is an open access article distributed under the terms and conditions of the Creative Commons Attribution (CC BY) license (https:// creativecommons.org/licenses/by/ $4.0 /)$.
Abstract: Green space exposure is beneficial to the physical and mental health of community residents, but the spatial distribution of green space is inequitable. Due to data availability, green equality or justice studies typically use administrative units as contextual areas to evaluate green spaces exposure, which is macro-scale and may lead to biased estimates as it ignores fine-scale green spaces (e.g., community gardens, lawns), that community residents are more frequently exposed to. In this study, we used the community as the unit of analysis, considered the green exposure of community residents in their daily social and physical activities, obtained data on three types of green spaces including fine-scale green spaces in the communities, surrounding large-scale parks and streetscape images. We propose a series of metrics for assessing community green equity, including a total of 11 metrics in three major categories of morphology, visibility and accessibility and applied them to 4544 communities in Beijing urban area. Through spatial visualization, spatial clustering, radar plots, and correlation analysis, we comprehensively analyzed the equity of green space at the community scale, identified the cold and hot spots of homogeneity, and then analyzed the equity of green space among regions under the urbanization process. The measurement results of these metrics showed that there are large differences and complementarities between different categories of metrics, but similarities exist between metrics of the same category. The proposed methodology represents the development of a green space evaluation system that can be used by decision makers and urban green designers to create and maintain more equitable community green spaces. In addition, the large-scale, comprehensive and fine-scale green space measurement of this study can be combined with other studies such as public health and environmental pollution in the future to obtain more comprehensive conclusions and better guide the construction and regeneration of green spaces.

Keywords: green justice; community green space; fine-scale green space analysis

\section{Introduction}

Exposure to community green space has proven to have a number of direct and indirect physical and mental health benefits. Direct benefits include relieving stress emotions [1], decreasing urban heat island effect [2], improving air quality and reducing respiratory disease mortality [3,4], type 2 diabetes outcomes [5-7], cardiovascular disease [8] and allcause mortality [9], while indirect benefits include promoting well-being feelings through the increase of sports and social activities in communities [10]. However, access to green space is an important environmental justice issue. Social segregation exists in the use of green space, which is related to socioeconomic status of residents, such as race, income, occupation and age $[11,12]$. Social isolation is manifested mainly in uneven access to green space, the housing displacement of vulnerable groups and differences in types of community green space, which makes green space equity more represents as residential problems. Thus, it is particularly important to facilitate neighbourhood green space assessment, both for green space justice and residents' health. 
Currently, studies investigating green space justice are increasingly common, there is considerable diversity in methods and definitions used to quantify equity. Three types of data are commonly used for assessing green space: census data [13], remote sensing data [14], land cove or land use databases [15-19]. However, none of these data could support a fine-scale green space assessment. Census data relating to socioeconomic deprivation and health is usually available only at aggregated administrative neighborhood scales, for example, in UK, the smallest unit at which data is made available in the Output Areas (OAs), which has an average population of 309. Remotely sensed data and land cover databases provide a relative fine-scale approach to green space estimation, but still face the challenge of the pixels' mosaics of buildings, squares, roads and green spaces in cities. The data still cannot provide the actual area and shape of each green space patch, and needs to be aided by GIS methods or manual editing.

There are four broad measures of community green space. Availability, also known as Provision, refers to the quantity of green space available in the community, which is the simplest and easiest to quantify and consequently the most common used type of metric, especially in studies of large areas. The metrics include greening rate, green coverage, NDVI, tree cover and so on $[16,17,20,21]$. Green space Morphology metrics not only delineate green cover conditions but also measure the morphology of green space, such as complexity, connectedness, aggregation, which are often ignored to be assessed, but have been clarified to be associated with all-cause and cause-specific mortality $[9,18]$. Visibility refers to the proportion of greenery in streetscapes and employs the green view index (GVI) as the main measure index. This perceived greenness generates more activities, higher aesthetic values and well-being for residents in vicinity of urban green spaces [22,23]. With the advert of open source street views (e.g., Google Street View, Tencent Street View and Baidu Street view) and deep learning techniques, green objects can be automatically identified by semantic segmentation methods, and GVI index and tree assests can be accurately computed along streets [24]. Accessibility is often operationalised as a distance to large area green space [25-29] or proportion of population within a given distance of large area green space [30]. Large parks, including regional parks, and national forests or parks, have special health, social and environmental benefits. Therefore, it is increasingly important to promote equitable access to large parks [31-34].

Scale effects can affect the results of equity estimation, especially for indicators that include population [35]. At larger scales, more supply decreases resource scarcity, but at smaller spatial scales, less supply reveals stronger inequity, reflecting the importance of studying green spatial equity at fine scales. Our comparison study also shows that there are more studies at the district level and census tract level where official census data are available. With the availability of open data, for example, area-of-interest data are available from commercial map providers, making fine-scale such as community-scale, household-scale studies possible. The results for community equity are quite diverse with different buffers around communities or households, and the distances to buffers used in the literature are quite different, ranging from 400 to $3200 \mathrm{~m}$, or 5-min to 15-min walking distance. Some studies simply use distance to nearest green space and avoid assuming an appropriate neighborhood size using Euclidean distance or network work distance, which may underestimate the green space condition when the assessment area is surrounded by several large areas of green space.

Given these limitations and implicit assumptions, the aim of this study is to provide a comprehensive and accurate green space assessment at an extremely fine-scale, thus allowing us to investigate the question of how green space equity geographically varies in communities, regions and even larger scales. We created a general-purpose set of metrics by combining the concepts of accessibility, morphology and visibility, assessing the green space ranging from the ground provision and morphology to the green proportions in humans' eyes, thus enabling us to understanding the green space equity from multiple dimensions in Beijing. The fine scale and comprehensive green space data obtained from map providers and pre-trained deep neural networks support us to fulfill the purpose. 
Compared with previous studies, our study outperformed in terms of number of communities and number of indicators in these community green space equity studies (See Table 1). The main contributions of this study are threefold: First, we fill a gap in analysis of green space morphology at very fine scales and over large areas. Secondly, we proposed a comprehensive set of green equity metrics in terms of morphology, visibility and accessibility, to support a comprehensive evaluation of community green spaces. Finally, this set of evaluation methods was tested in the study area to verify the feasibility of the method, which can be later used in other analysis units and other areas of combined research.

Table 1. A comparison between representative studies of community green space equity and our study.

\begin{tabular}{|c|c|c|c|c|c|}
\hline Study Unit & No. of Units & Location & Green Spaces & Metrics & Paper \\
\hline \multirow[t]{5}{*}{ Sub-district } & 447 & Berlin, Germany & land cover & availability & [16] \\
\hline & 186 & Munich, Germany & land cover & availability & [17] \\
\hline & 63 & Leipzig, Germany & land cover & morphology & [18] \\
\hline & 58 & Shenzhen, China & public green space & availability & [21] \\
\hline & 41 & Hangzhou, China & urban park & accessibility & [26] \\
\hline \multirow[t]{6}{*}{ Census tract } & 71,763 & USA & public green space & accessibility & {$[27]$} \\
\hline & 58,733 & South Africa & green infrastructure & availability & [36] \\
\hline & 28,412 & USA west & large parks & accessibility & [37] \\
\hline & $3000+$ & $\begin{array}{l}\text { Hannover, } \\
\text { Germany }\end{array}$ & land cover & availability & [38] \\
\hline & 323 & Singapore & urban park & park availability & [35] \\
\hline & 127 & Baltimore, USA & urban park & accessibility & [34] \\
\hline \multirow[t]{2}{*}{ Park } & 2143 & New York, USA & urban park & $\begin{array}{c}\text { human visitation } \\
\text { dynamics }\end{array}$ & [32] \\
\hline & 162 & Phoenix, Arizona & urban park & availability, quality & [33] \\
\hline Schools & 324 & Barcelona, Spain & school greening & availability & [39] \\
\hline \multirow[t]{8}{*}{ Community } & 4524 & Brisbane, Australia & public green space & availability, accessibility & [40] \\
\hline & 2897 & Wuhan, China & $\begin{array}{l}\text { green spaces in the } \\
\text { community }\end{array}$ & accessibility & [28] \\
\hline & 2494 & Zhengzhou, China & urban park & accessibility & [29] \\
\hline & 1799 & Dalian, China & public green space & availability and visibility & [23] \\
\hline & 615 & Xuzhou, China & public green space & quality and accessibility & [41] \\
\hline & 163 & Wuhan, China & public green space & accessibility & [42] \\
\hline & 145 & Brussels, Belgium & land cover & $\begin{array}{l}\text { availability and } \\
\text { accessibility }\end{array}$ & [19] \\
\hline & 99 & Aleppo, Syria & urban park & accessibility & [43] \\
\hline Our study & 4544 & Beijing, China & public green space & $\begin{array}{c}\text { accessibility, morphology } \\
\text { and visibility }\end{array}$ & \\
\hline
\end{tabular}

\section{Materials and Methods}

\subsection{Study Area}

Beijing, as the capital of China, has a 2000-year history of urban settlement and has become a cosmopolitan city in recent decades, with a typical layout consisting of a single center with several surrounding concentric ring roads, and a distinct development difference between the southern and northern city distinguished by the east-west Chang'an Avenue, as shown in Figure 1b. By the end of 2020, the population of permanent residents reached 21.8 million, with population density and urbanization decreasing as the ring roads move farther away from the city center. The size of the main built-up area (located within 5th ring road, as shown in Figure 1a) is approximately $660 \mathrm{~km}^{2}$, with a total green area of $195.7 \mathrm{~km}^{2}$. There are 4544 residential communities within Beijing's 5th Ring Road, with approximately $10.8 \mathrm{~km}^{2}$ of green space within the communities.

In this study, we evaluated the condition of green space in and around residential communities. Residential communities are basic living units, usually with well-defined fences or wall boundaries, with several residential buildings and public spaces built for physical and social activities of residents, and are a central element of urban greenery. 
Data on residential communities in the study area were obtained by accessing the AOI (area of interests) information from the Application Programming Interface (API) of Amap (accessed on 5 November 2021, in Chinese only), a local-road navigation company based in Beijing . A total of 4544 residential communities and their boundaries within the 5 th Ring Road of Beijing were obtained for further analysis, as shown in Figure 1b.

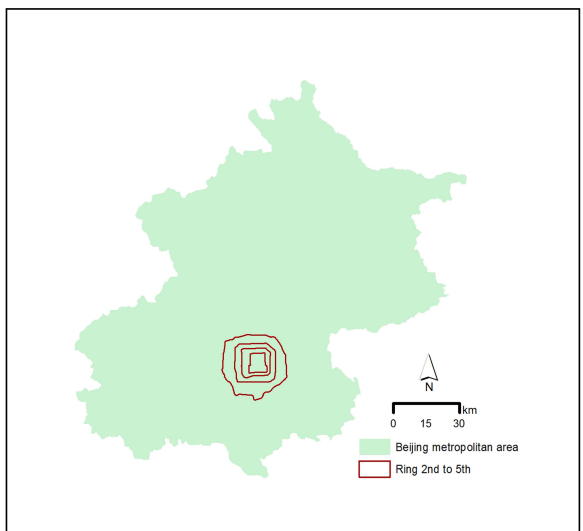

(a)

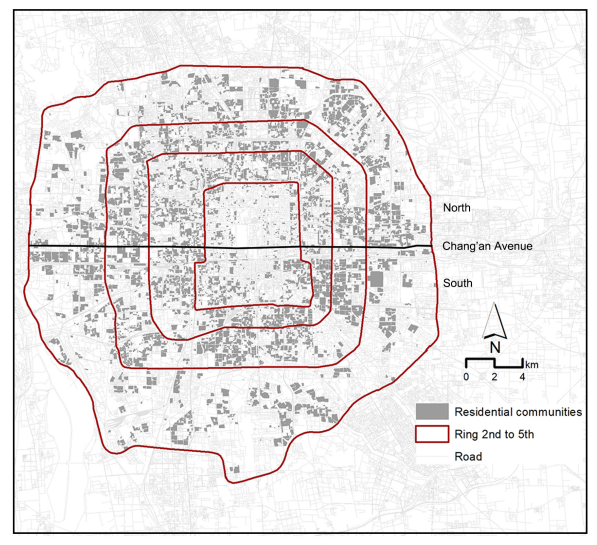

(b)

Figure 1. (a) The built-up area within the 5th Ring Road of Beijing as the study area; (b) 4544 residential communities in the study area as the analysis unit.

\subsection{Data Sources}

This study acquired a full range of green space data in and surrounding the communities, including green spaces inside the community, large parks around the community, and green spaces perceived in the street view images.

The fine-scale community green space data was downloaded from Bigemap Software, which provides a vector map layer at the architectural scale, allowing highly accurate analysis of land use. We downloaded the vector map tiles in the 5th Ring of Beijing and imported them into ArcGIS. These map tiles are provided in the WGS 1984 projection, which allows ArcGIS to automatically locate and merge the map tiles. Polygons with green color were extracted and designated as green space shapefile for the purpose of our analysis. The fine-scale green space within communities, which are often ignored and generalized in other commercial maps or remote sensing interpretation results, are very clearly outlined in the shape of each patch in Figure 2a, which allows us to investigate the total area and each green patch within communities, thereby supporting the calculation of the following green metrics on a fine scale. The green space category of the community can be described as landscape around buildings, community gardens and street trees, as shown in Figure 2b. However, these types of green spaces are excluded from the commercial map services and are difficult to retrieve from remotely sensed data due due to satellite photography views and occlusions, which reveals the importance of this fine-scale dataset.

Figure 2c depicts the green spaces seen in the street view images, which were obtained through the Baidu Map API (accessed on 5 November 2021, in Chinese only). First, based on the road network acquired from AMap, the road network is simplified and merged into single roads. Then each processed road segments are divided into vertices with a distance of $50 \mathrm{~m}$ and the coordinates of each vertex are stored. The coordinates are input into Baidu Map API for downloading street view images at this coordinate. The API are requested four times at each coordinate with different heading angles $(0,90,180,240)$ to achieve a full view of this point. Finally, approximately 45,806 points with 183,224 images are obtained in the study area.

Park boundaries with an area of over $10 \mathrm{ha}$, which is the standard for metropolitan parks in China, were identified from the parks and squares category of the 2019 Amap AOI data, as shown in Figure 2d. A total of 94 large parks were downloaded within the 5th Ring of Beijing. 

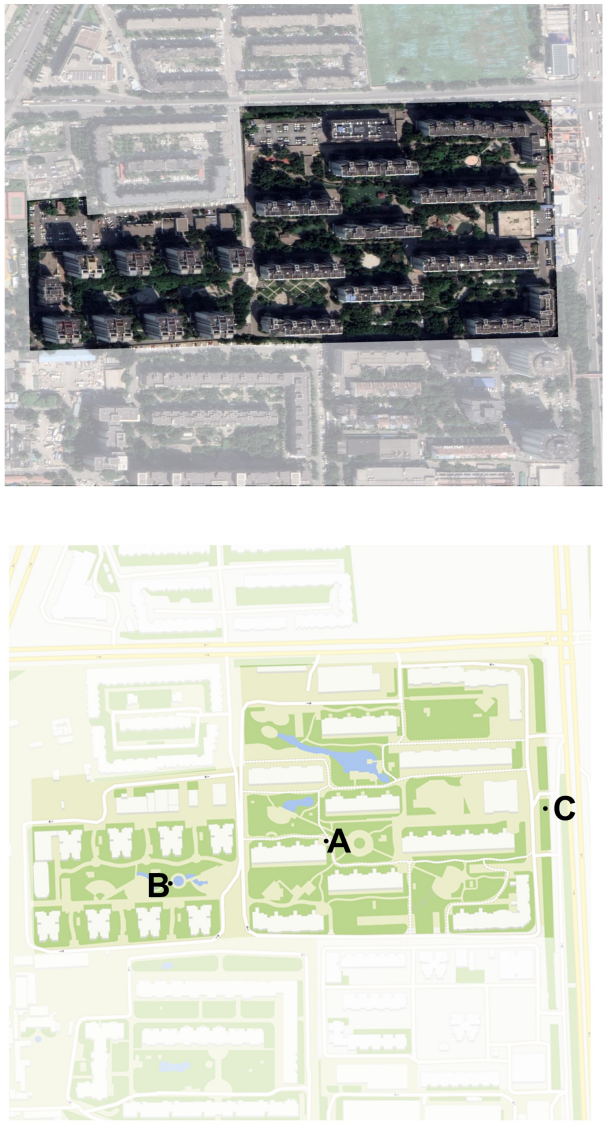

(a)
Type A

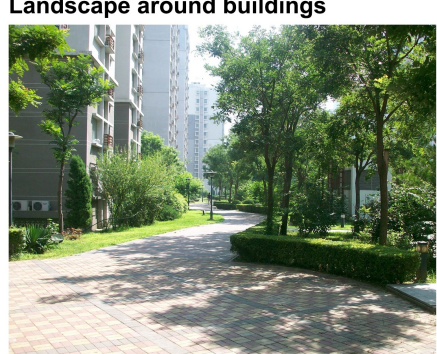

Type B
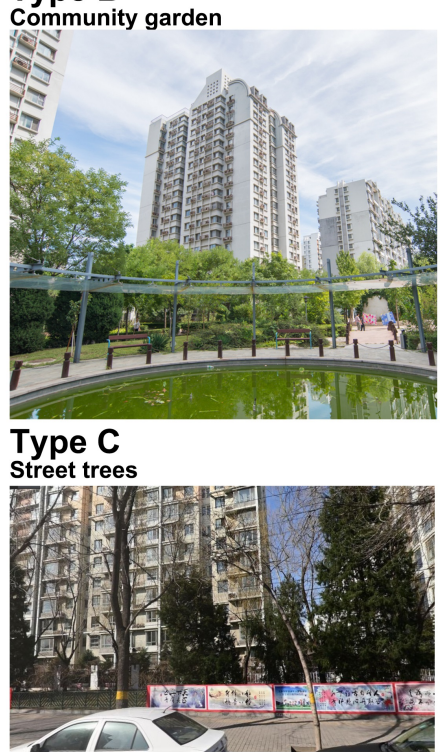

(b)
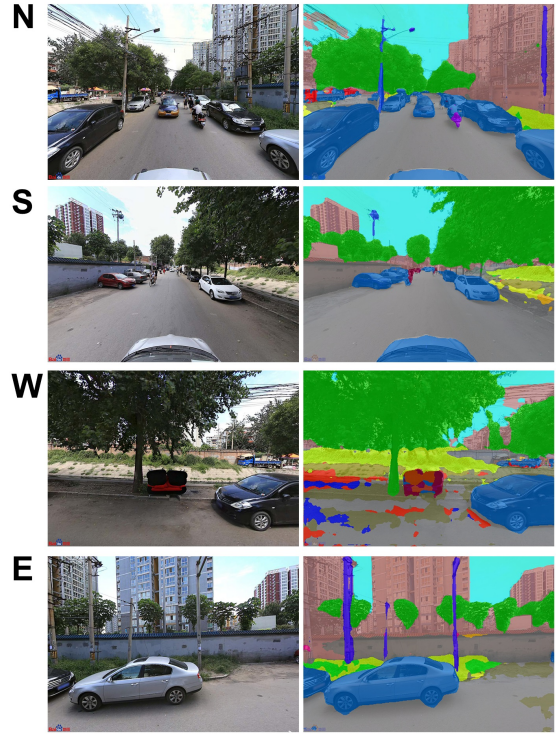

(c)

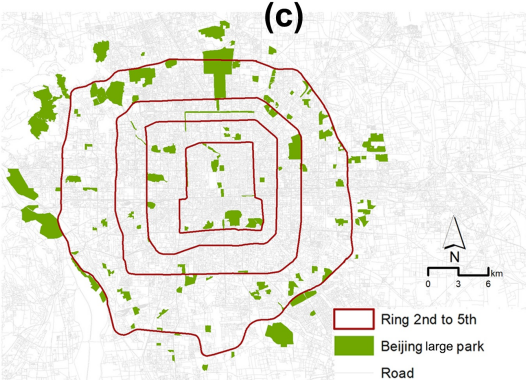

(d)

Figure 2. Data sources: (a) Green spaces in the communities from Bigemap, (b) types of green spaces in the communities, (c) green spaces seen in Baidu street view images, (d) large parks surrounding the communities from AMap.

\subsection{Green Equity Metrics}

Based on the daily social and physical activities of residents in the community and the impact of community green spaces on residents, this study analyzed three categories of green space equity metrics, namely morphology, accessibility and visibility. Since the availability indicator, usually the number of green spaces, is already covered in the morphological indicators, we finally selected the more comprehensive morphological indicator in the methodology.

\subsubsection{Morphology Metrics}

Seven morphology metrics are designed to analyze the morphology of green spaces within the communities. Six indicators of greenspace morphology in cities, with the exception of PBUILD, have been proved to have a significant modest association with mortality risk [9]. The community green space data we processed from Bigemap afford us a chance to calculate six morphology metrics at extremely fine scale using FRAGSTATS software (accessed on 5 November 2021), including percentage of green space (PLAND), mean area of green space (AREA_MN), fragmentation of green space (PD), green space connectedness (COHESION), aggregation of the green space pattern (AI) and complexity of the shape of the green space (SHAPE_AM). While higher PBUILD, which can be considered as greenspace per capita, has been shown to be associated with a reduced risk of cardiovascular disease [44]. To represents green space per capita, we calculated PBUILD metric using ArcGIS. The descriptions and formulations of the metrics are as follows: 
Percentage of green space $P L A N D_{i}$ equals the sum of the areas of all green patches in the community $i$ divided by the total community area $A_{i}$, multiplied by 100 (to convert to a percentage).

$$
\operatorname{PLAND}_{i}=\text { Green }_{i} / A_{i}(100)
$$

Mean area of green space (AREA_MN) equals the sum of the areas of all green patches divided by the number of patches $n_{i}$ in the community $i$.

$$
\text { AREA_MN } N_{i}=\text { Green }_{i} / n_{i}
$$

Fragmentation of green space $P D_{i}$ equals the number of green patches in community $i$ divided by total community area $A_{i}$, multiplied by 10,000 and 100 (convert from $\mathrm{m}^{2}$ to hectares, which means the number of patches per 100 hectares).

$$
P D_{i}=n_{i} / A_{i}(10,000)(100)
$$

Green space connectedness measures the physical connectedness of the corresponding patch type. COHESION ${ }_{i}$ [45] equals 1 minus the sum of patch perimeter divided by the sum of patch perimeter in terms of pixels times the square root of patch area in terms of pixels, divided by the 1 minus 1 over the square root of the total number of pixels, denoted $Z$. Where the perimeter of patch $j$ in community $i$ is denoted $p_{i j}$ and the area is denoted $a_{i j}$.

$$
\operatorname{COHESION}_{i}=\left[1-\frac{\sum_{j=1}^{n} p_{i j}}{\sum_{j=1}^{n} p_{i j} \sqrt{a_{i j}}}\right] /\left[1-\frac{1}{\sqrt{Z}}\right](100)
$$

Aggregation of the green space pattern $A I_{i}$ is calculated from an adjacency matrix, which shows the frequency with which different pairs of green patches appear side-byside on the map. $A I_{i}$ equals the number of like adjacencies divided by the maximum possible number of like adjacencies, multiplied by 100 (to covert to a percentage). $g_{j j}$ is the number of like adjacencies between pixels of green space based on the single-count method, $\max -g_{j j}$ is the maximum number of like adjacencies between pixels of green space based on single-count method.

$$
A I_{i}=\left[\frac{g_{j j}}{m a x-g_{j j}}\right]
$$

Complexity of the shape of the green space $S H A P E_{-} A M_{i}$ is also called area-weighted mean shape index. Shape index $S H A P E_{i}$ is given as the patch perimeter divided by the patch perimeter of a square patch of the same size. SHAPE_AM $M_{i}$ is the area-weighted average of $S H A P E_{i}$, which provides a standardized measure of total edge or edge density that adjusts for the size of the patch. SHAPE_AM $M_{i}=1$ means the community consists of a single square patch. $S H A P E_{-} A M_{i}$ increases without limit as patch shape becomes irregular or the length of edge within the patch increases.

$$
\text { SHAPE_AM }=\frac{\sum_{j=1}^{n} a_{i j} * \frac{0.25 p_{i j}}{\sqrt{a_{i j}}}}{A_{i}}
$$

Finally, green area per capita $P B U I D_{i}$ corresponds to the ratio of the entire green space area to the floor area of all buildings in the community $i$. The floor area of a buildings is the sum of the area of each floor of the building and can be used to represent the size of the community residents. 


$$
\text { PBUID }_{i}=\text { Green }_{i} / \text { Building }_{i}(100)
$$

\subsubsection{Visibility Metric}

The visibility metric represents the green space seen and perceived by community residents during physical and social activities. In this study, residents' activity areas were defined as a 200-m Euclidean buffer around the community, which represents a 10-min walking distance. The rationale for selecting this distance is that under the influence of COVID-19, community green spaces that are privately owned by residents have a greater protective effect on health when strict blockade restrictions discourage people from going to green spaces that are more than $10 \mathrm{~min}^{\prime}$ walk away [46].

Within the 10-min walking circle, an image segmentation model was used to automatically identify the greenery residents can see, which includes tree, grass, mountain, plant, flora, flower and palm tree. The model is implemented with Deeplab v3+ framework and Xception model trained on ADE20K dataset (accessed on 5 November 2021) is used to perform semantic segmentation. After identifying the greenery in each image, the pixel proportion of these greenery is calculated as the green view index (GVI) of this image. The GVI value at this point is the average of the GVIs of the four-directional images. Consequently, the visibility metric is the average of the GVI values of all street points in the community buffer, and the formula is written as follows:

$$
G V I \_200_{i}=\sum_{j} G V I_{i j} * L_{i j} / \sum_{j} L_{i j}
$$

where $G V I_{i j}$ is the average GVI of the $j$-th road in the buffer of community $i$, whose length is $L_{i j}$.

\subsubsection{Accessibility Metrics}

The accessibility metric is used to describe the accessibility to the large parks surrounding the community. In this study, three scales were chosen to describe the accessibility of surrounding large parks, namely $1 \mathrm{~km}, 2 \mathrm{~km}$, and $3 \mathrm{~km}$, respectively, in order to avoid the potential bias caused by a single-scale buffer. The size of large parks in Beijing ranges from 10.05 hectares (Wangjing Park) to 971.67 hectares (Beijing Olympic Park). On the basis of communities buffers of $1 \mathrm{~km}, 2 \mathrm{~km}$ and $3 \mathrm{~km}$, the size of large parks within the buffer zone was calculated using ArcGIS spatial join tool. Here, if a part of the park, rather than an entrance, was within the buffer zone, we calculated the area of the entire park, because large parks not only provide benefits to visitors entering the park, but also generate significant ecological benefits [47].

\section{Results and Discussions}

\subsection{Community Inequity}

In this section, we discussed the analysis results of three types of equity metrics. Table 2 provides descriptive statistics on the green equity metrics of 4544 communities in Beijing urban area. Referring to the conclusion in [9], all morphological indicators except PD were negatively associated with all-cause mortality, therefore, all the indicators except PD can be considered to be more beneficial to humans with larger values. Among them, regarding PLAND, refer to the Chinese national standard "General Rules for Planning and Design of Construction Works on Beijing Sites", which stipulates that PLAND should not be less than $30 \%$, but in our evaluation, the mean value did not reach this standard, which is a cause for concern.

Figure 3 plots the correlation matrix of the 11 metrics, which allows for better metric selection and use in related studies. It can be seen that there is no significant correlation between the three categories of metrics, reflecting the three aspects of green space in the community: green space in the community, perceived greenness, and large parks outside the community, indicating that the three categories have good complementarity 
and integrity. There are some correlations among the morphological metrics, such as PLAND and SHAPE_AM, which reflects the percentage and complexity of green space, respectively, and the correlation between them and other morphological metrics are greater than 0.3. The correlation between COHESION and AI is as high as 0.99 , which indicates that the higher the connectivity and the higher the aggregation in the community green space.

Table 2. Descriptive statistics of green equity metrics in 4544 communities in Beijing urban area.

\begin{tabular}{|c|c|c|c|c|}
\hline Variable & Mean & Minimum & Maximum & Std.dev. \\
\hline \multicolumn{5}{|l|}{ Morphology metric } \\
\hline Percentage of green space (PLAND, [0-100\%]) & 14.38 & 0.00 & 75.17 & 13.01 \\
\hline Green area per capita (PBUILD, $\left.>0 \mathrm{~m}^{2}\right)$ & 0.08 & 0.00 & 6.41 & 0.16 \\
\hline Aggregation of green space (AI, [0-100\%]) & 78.37 & 0.00 & 100.00 & 33.56 \\
\hline Green space connectedness (COHESION, $[0,100])$ & 80.85 & 0.00 & 99.88 & 34.50 \\
\hline Mean area of green space (AREA_MN, >0 m²) & 0.06 & 0.00 & 3.18 & 0.12 \\
\hline Complexity of the shape of green space (SHAPE_AM, >1) & 1.82 & 0.00 & 14.39 & 1.03 \\
\hline Fragmentation of green space $(\mathrm{PD},>=0$ per $100 \mathrm{ha})$ & 371.36 & 0.00 & 6017.51 & 386.54 \\
\hline \multicolumn{5}{|l|}{ Visibility metric } \\
\hline Green view index (GVI, $[0,4])$ & 0.07 & 0.00 & 1.91 & 0.07 \\
\hline \multicolumn{5}{|l|}{ Accessibility metric } \\
\hline 1KM_access (ha) & 75.21 & 0.00 & 1130.42 & 166.77 \\
\hline 2KM_access (ha) & 199.32 & 0.00 & 1210.00 & 254.41 \\
\hline 3KM_access (ha) & 370.27 & 0.00 & 1527.18 & 324.77 \\
\hline
\end{tabular}

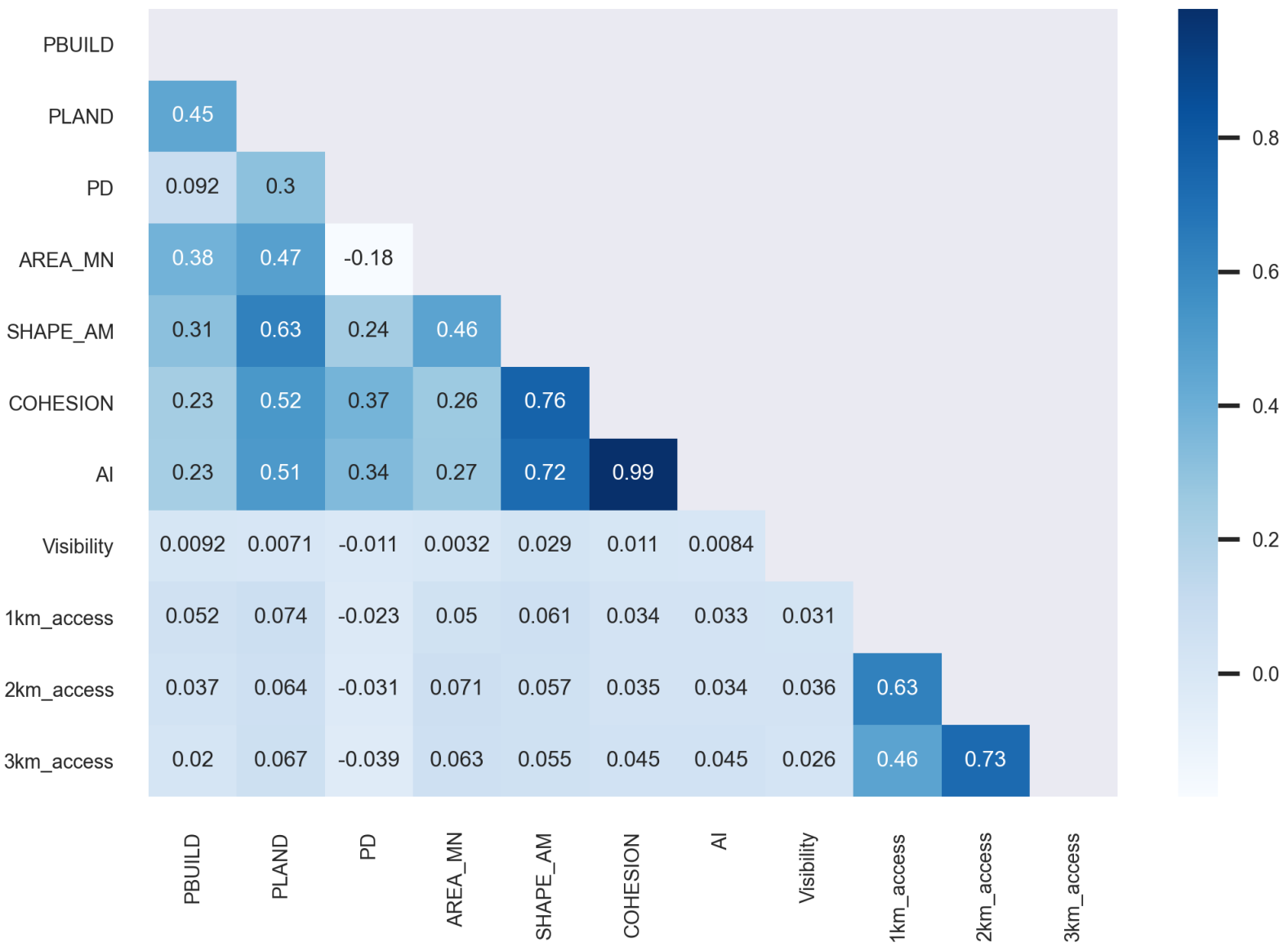

Figure 3. Correlation matrix of 11 green equity metrics. 


\subsubsection{Morphology}

Figure 4 shows the results of the 7 morphological indicators, including percentage of green space (PLAND), mean area of green space (AREA_MN), fragmentation of green space $(\mathrm{PD})$, green space connectedness (COHESION), aggregation of the green space pattern (AI), complexity of the shape of the green space (SHAPE_AM) and green area per capita (PBUILD). All metrics except the PD metric presented a trend of increasing values outward from the inner to the outer ring, with the most pronounced monocentric distribution characteristic of AREA_MN. AREA_MN measures the average green area within the communities. The communities in the highest quartile are basically located in outermost ring of Beijing, and communities within the 2nd ring are basically in the lowest two quartiles, as communities in this area are relatively small and have extremely limited and scattered available green space areas due to several important urban heritage sites and numerous historical buildings. PLAND and PBUILD are two relatively evenly distributed metrics with high values. These two metrics mainly measure green space coverage and do not involve complex morphology, indicating that even small communities can build green space that meet basic size requirements and that the morphology of each green space is not necessarily complex. The only metric that has an opposite trend to the overall high and low values is the PD metric, which measures the degree of fragmentation of green spaces. Its lowest quartile is mostly in the outermost part of an urban area, between 4th to 5th rings. The lower the value, the less fragmented and more intact the green space is, which has been proven to have health benefits and can reduce the mortality rate [9]. Thus, despite the opposite trend of the PD metric, the effect is indeed the same, i.e., the community green space morphology develops better from the inner to the outer ring.

\subsubsection{Visibility}

The result of visibility metric is shown in Figure 4 . It can be seen that there is no obvious monocentric characteristic of visibility from the 2nd to the 5th ring; instead, the visibility layer shows a relatively balanced distribution. Even so, there are still several clusters with higher and lower values. The southeast corner and west side between the 2nd and 3rd rings, as well as the northern part between the 2nd and 4th rings are high-value agglomeration areas. This is due to the presence of several large parks nearby, such as the Olympic Green Park in the central north, which leads to better green planting in the surrounding area.

\subsubsection{Accessibility}

The Figure 4 shows that the accessibility values for Beijing's urban areas gradually increase from $1 \mathrm{~km}$ to $3 \mathrm{~km}$ in the north (the north and south areas of Beijing bounded by Chang'an Avenue), with particular high values for the area between 3th and 5th rings. The northern region has many large parks, Chaoyang Park in the northeast, Olympic green park in the north-central part, and a series of Beijing's Qing Dynasty royal gardens in the northwest, which has been a concentration of large parks since 100 years ago, including two Summer Palaces (Yiheyuan and Yuanmingyuan), all of which are now open to the public as urban parks. Most of the southern part of Beijing has lower accessibility values, with higher values only in the southeast, which was also a former royal garden of the Qing Dynasty. Similar to the visibility metric, most of the areas within the 2nd Ring Road are in the upper third quartile area, especially the southeastern part of the 2nd Ring Road. There is the Temple of Heaven Park, a place where the ancient emperors worshiped the heavens, now open to the public as a large park. All citizens have equal access to these parks and the prices of annual or single-entry passes are affordable, so affordability is not the main factor affecting park accessibility; the proper distribution of large parks is more important. 


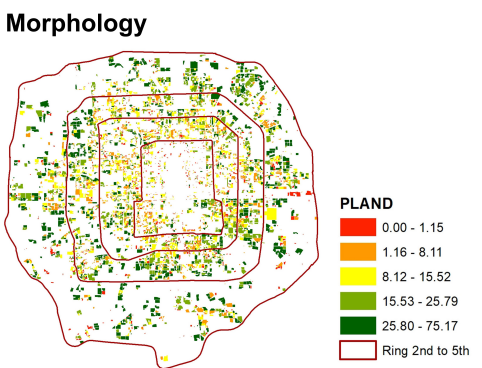

(a)

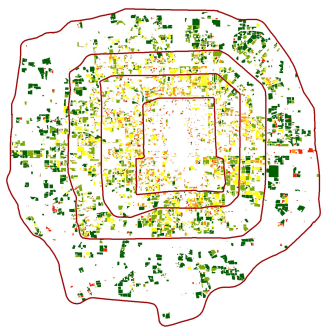

(d)
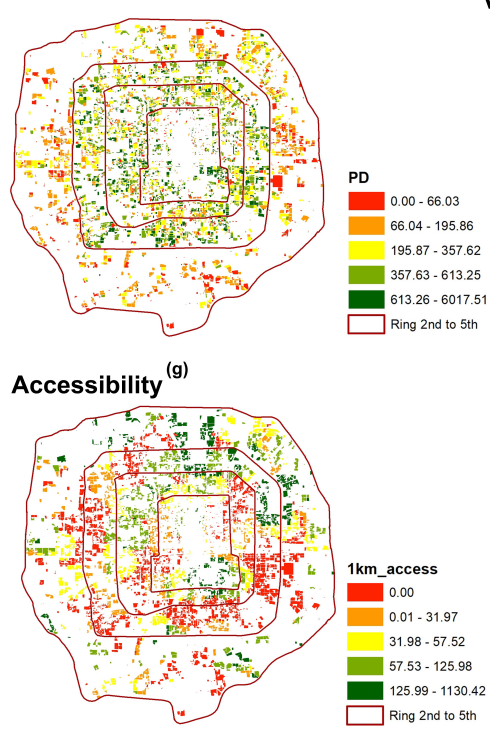

(i)

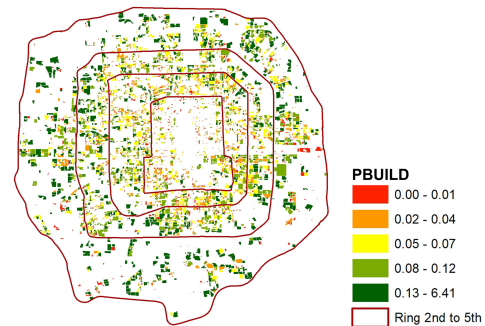

(b)

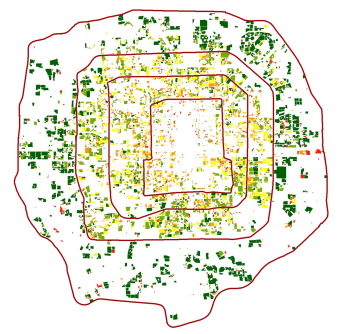

(e)

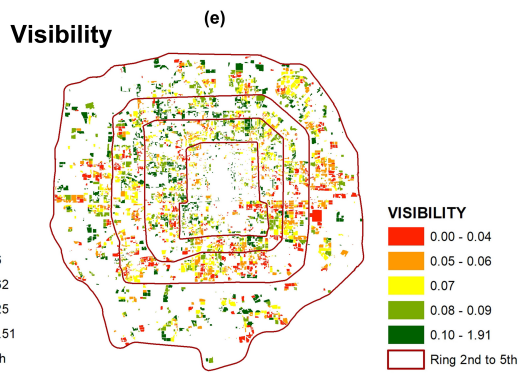

(h)

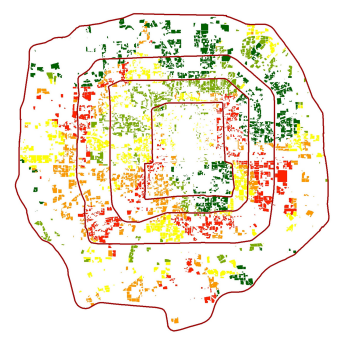

(j)

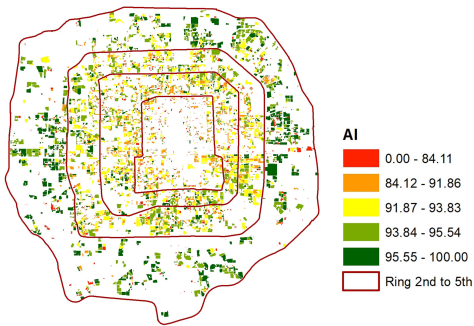

(c)

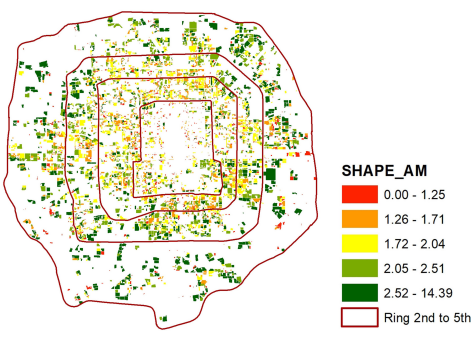

(f)
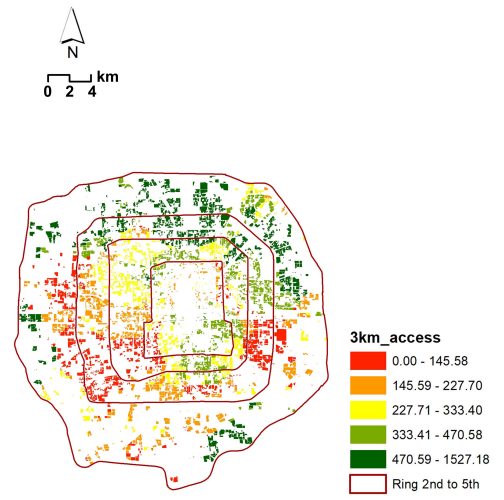

(k)

Figure 4. Measurement results of 11 green equity metrics for residential communities within the 5th ring of Beijing, in terms of morphology (a-f), visibility (g,h) and accessibility (i-k).

\subsection{Spatial Clusters}

Through spatial cluster analysis, areas with good and poor green space conditions (i.e., hot and cold spots) were identified, thereby reflecting protective and harmful effects on humans, respectively (See Figure 5). In terms of morphological metrics, all the hot spot clusters show a tendency for cold spots to be in the inner city and hot spots to be in the periphery. Because smaller PD values represent more benefits to residents, we consider the identified cold spots as hot spots, which could be consisted with results with other metrics. Similar to the original results, the hot spots of AREA_MN are basically in the middle of 4th and 5th rings. SHAPE_AM, GREEN_PER and PLAND are also distinctly different in the inner and outer rings. In contrast, PLAND has more hot and cold spots, while SHAPE_AM has a tendency to spread to the periphery, with a few cold spots between 3rd and 5th rings. COHESION and AI have similar cold spots as the other metrics, but the hot spots appear in the central of the city, such as the northeast and north of the rings $2-4$ and the west of the rings $2-3$ rings. 


\section{Morphology}

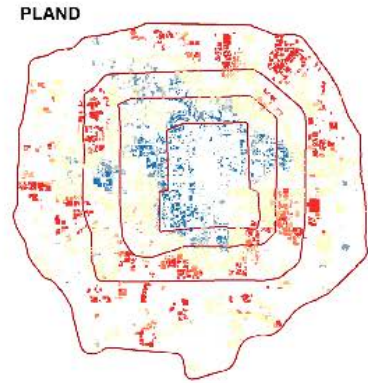

(a)

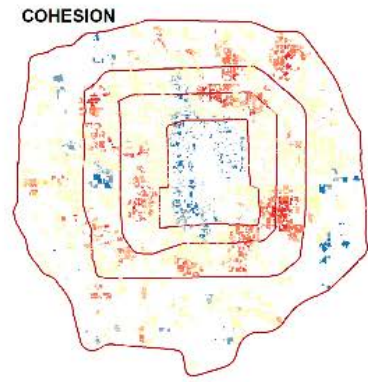

(d)

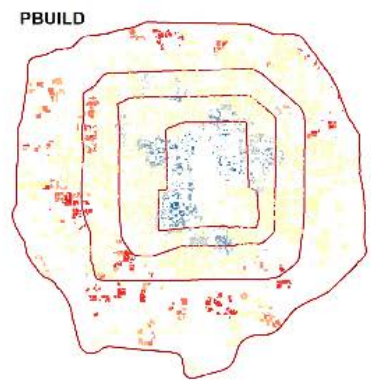

Accessibility ${ }^{(g)}$

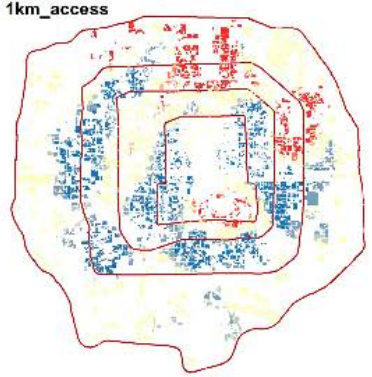

(i)

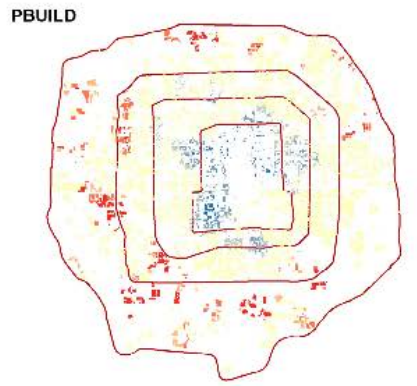

(b)

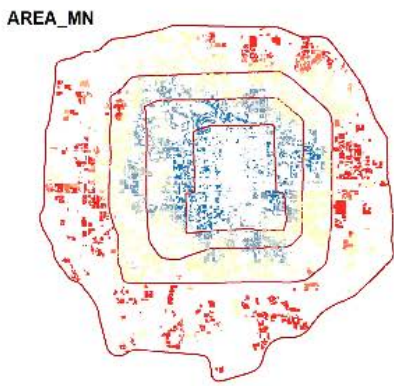

(e)

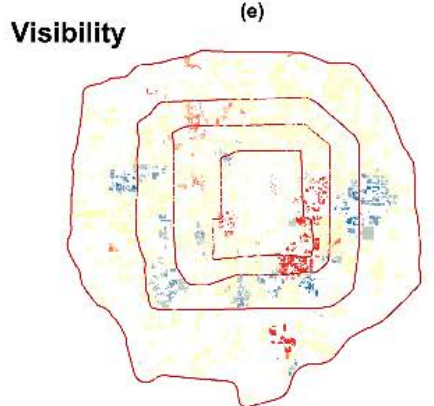

(h)

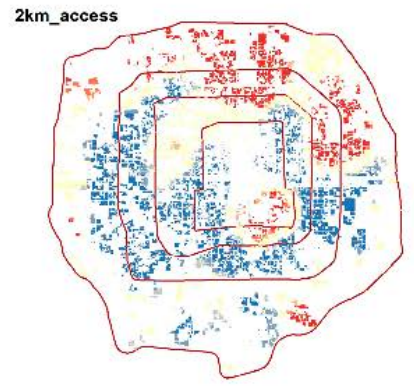

(j)

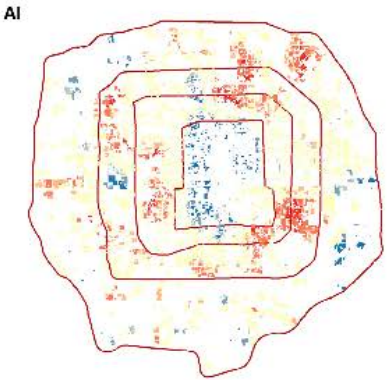

(c)

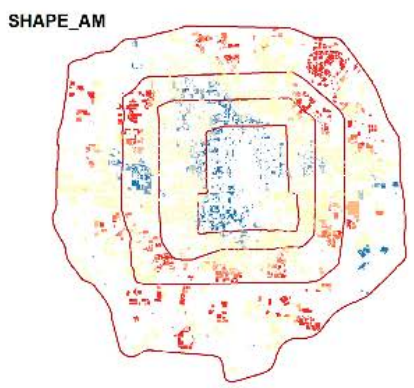

(f)
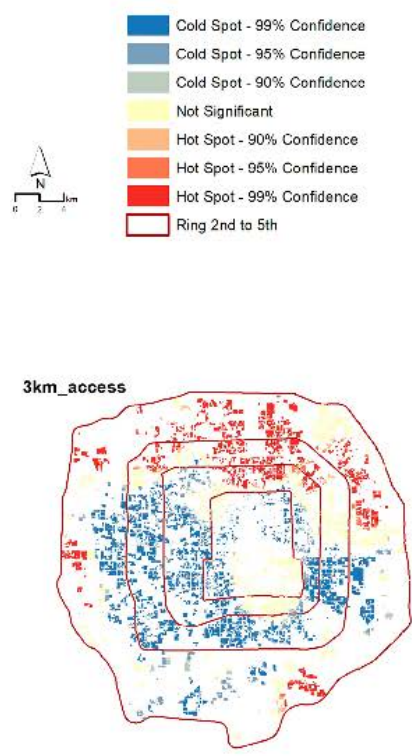

(k)

Figure 5. Spatial clusters of 11 green inequity metrics, in terms of morphology (a-f), visibility (g,h) and accessibility (i-k). Areas with good and poor green space conditions (i.e., hot and cold spots) reflects protective and harmful effects on humans, respectively.

In general, the northwestern part of the 3-4 ring and the northeastern part of the 4-5 ring are the areas where the hot spots are more consistent across metrics, namely Wangjing CBD (where there are many emerging Internet companies and traditional multinational conglomerates, and it is the top-ranked CBD in Beijing, aiming to build an ecological CBD), and Wanliu high-quality residential area (with high housing price and more surrounding green parks, such as Haidian Park, Summer Palace and Xiangshan Park).

On the contrary, most of the areas within the 2nd ring are cold spots with different metrics. The area within the 2nd ring is the scope of the Ming and Qing dynasty Beijing city, traditional Beijing area, and most of the internal gated-communities were built in the 
1950s-1970s, which are old and small in size, resulting in poor green space morphological metrics.

The clustering analysis of the visibility metric is completely different from the results of morphological metrics, first of all, the number and range of cold and hot spots are much less, and no longer have the characteristics of low inside and high outside. Accordingly, the hot spot areas are mainly concentrated inside the 4th ring, especially in the area of the 3rd ring where the morphological index value is low, while the hot spot areas of the morphological index, between the 3rd and 5th rings, are instead the areas where the cold spot areas of the visibility metric are concentrated. This indicates that, compared to the peripheral areas with better greenery inside the communities, the traditional urban core areas have insufficient green spaces inside the communities, but the road networks around the residential areas has higher density, and the planting of street trees makes the street greener, which partly compensates for the lack of green space within the communities. In addition, the hot spots of visibility metric overlap with the hot spots of PLAND, AI and COHENSION, mainly in the southeast corner between 2 nd and 3rd rings.

\subsection{Region Inequity}

The regional development model is closely related to the equity of green space, so it is necessary to analyze the green space in combination with the development model of the study area. Under the single-center development model in Beijing, there is obvious inequality in the development of communities between the ring roads and between the north and south regions. As can be seen from Table 3, the number of residential communities within the 2nd ring is the smallest, and the number of communities between the outer rings does not differ much, but the total, average and maximum area of residential neighborhoods is gradually increasing from the inside to the outside. In terms of north-south differences, the number of residential communities in the north of all regions is greater than the number of that in the south, but the average area of residential communities in the south is relatively larger.

Here we used the radar map to identify the different values of indicators in different regions, each corner represents the north-south direction of different rings of Beijing, corresponding to each Location in Table 3, and the ups and downs of the radar map can clearly indicate the inequality of different locations. As shown in Figure 6, in terms of morphology, PLAND, AI, COHESION, SHAPE_AM show similar distribution trends, except for the northern half of the second ring, the distribution of the remaining regions is relatively balanced; PBUILD and AREA_MN have higher values between the 4th and 5th rings, while the rest of the regions have lower values, with the lowest value in the northern part of the 2nd ring; in contrast, PD has the lowest value between the 4th and 5th rings. The distribution of visibility is relatively balanced within the five rings. Accessibility differs greatly between the north and south regions within different buffer, where the value of the northern region is higher than the value of the southern region outside the 2nd ring shows a very obvious feature.

Table 3. Descriptive statistics of the community area in the northern and southern rings.

\begin{tabular}{|c|c|c|c|c|c|c|}
\hline Location & Number & $\begin{array}{l}\text { Total } \\
\left(\mathrm{m}^{2}\right)\end{array}$ & $\begin{array}{l}\text { Mean } \\
\left(\mathrm{m}^{2}\right)\end{array}$ & $\underset{\left(\mathrm{m}^{2}\right)}{\operatorname{Minimum}}$ & $\begin{array}{l}\text { Maximum } \\
\qquad\left(\mathrm{m}^{2}\right)\end{array}$ & Std.dev. \\
\hline $\begin{array}{l}\text { Inside 2nd Ring } \\
\text { (South) }\end{array}$ & $670(346)$ & $\begin{array}{c}8,882,000.58 \\
(5,795,715.19)\end{array}$ & $\begin{array}{c}13,256.72 \\
(16,750.62)\end{array}$ & $562.32(685.18)$ & $\begin{array}{c}189,597.8 \\
(189,597.80)\end{array}$ & $\begin{array}{c}17,222.89 \\
(19,960.47)\end{array}$ \\
\hline $\begin{array}{l}\text { 2nd to 3rd Ring } \\
\text { (South) }\end{array}$ & $1333(509)$ & $\begin{array}{c}27,881,755.41 \\
(12,895,663.83)\end{array}$ & $\begin{array}{c}20,916.55 \\
(25,335.29)\end{array}$ & 634.5 (1066.27) & $\begin{array}{c}219,799.22 \\
(219,799.22)\end{array}$ & $\begin{array}{c}25,974.5 \\
(28,810.88)\end{array}$ \\
\hline $\begin{array}{l}\text { 3rd to } 4 \text { th Ring } \\
\text { (South) }\end{array}$ & $1313(621)$ & $\begin{array}{c}38,013,173.23 \\
(20,238,669.91)\end{array}$ & $\begin{array}{c}28,951.39 \\
(32,590.45)\end{array}$ & 741.42 (1049.51) & $\begin{array}{c}414,509.68 \\
(317,952.26)\end{array}$ & $\begin{array}{c}35,840.47 \\
(38,565.36)\end{array}$ \\
\hline $\begin{array}{l}\text { 4th to 5th Ring } \\
\text { (South) }\end{array}$ & 1238 (527) & $\begin{array}{c}53,438,908.1 \\
(24,966,082.68)\end{array}$ & $\begin{array}{c}42,566.25 \\
(47,373.97)\end{array}$ & $458.8(458.8)$ & $\begin{array}{c}1,066,110.29 \\
(1,066,110.29)\end{array}$ & $\begin{array}{c}54,984.38 \\
(65,109.78)\end{array}$ \\
\hline
\end{tabular}


PLAND

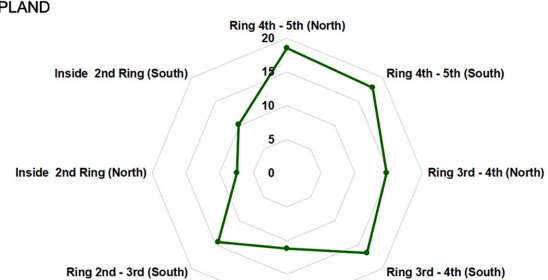

Ring 2nd - 3rd (North)

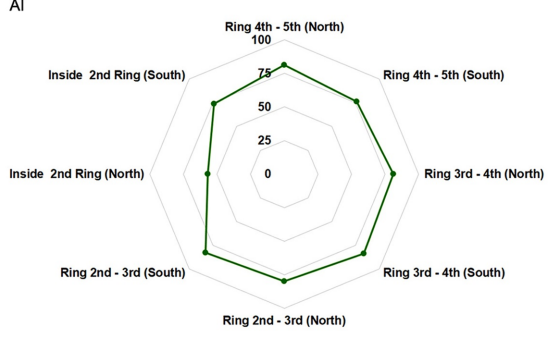

AREA_MN

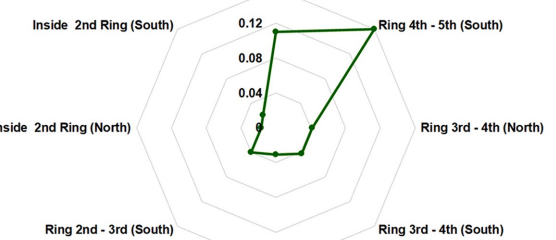

PD

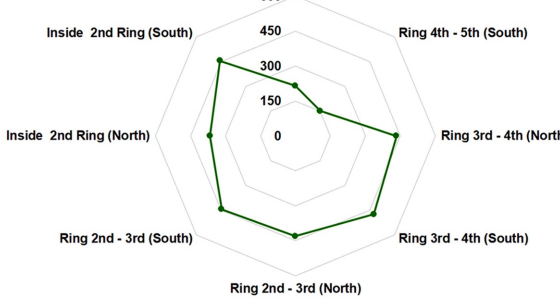

$1 \mathrm{~km} \_$access

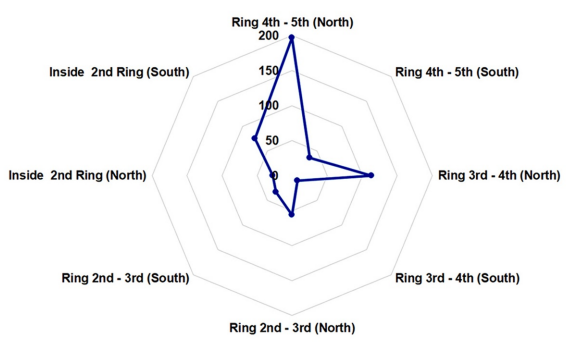

$3 \mathrm{~km} \_$access

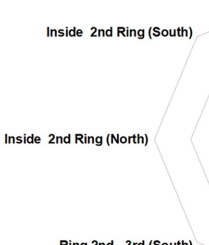

Ring 2nd - 3rd (South)

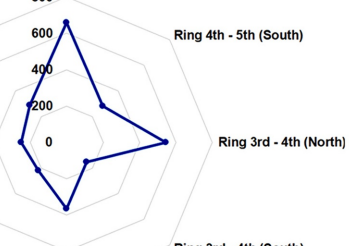

Ring 2nd - 3rd (North)

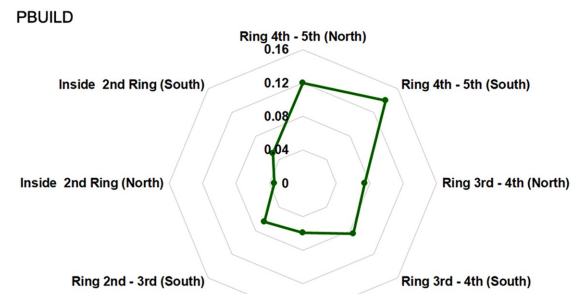

Ring 2nd - 3rd (North)

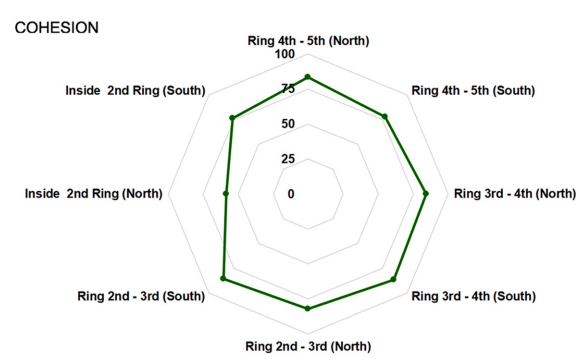

SHAPE_AM

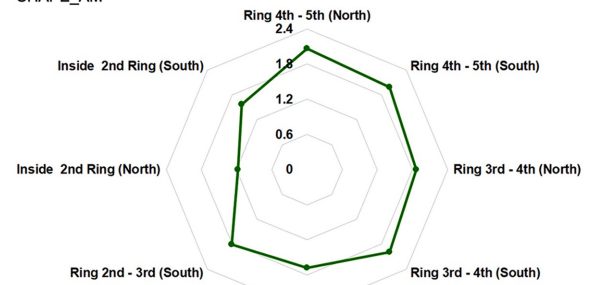

Ring 2nd - 3rd (North)

VISIBILITY

Ring 4th - 5 th (North)

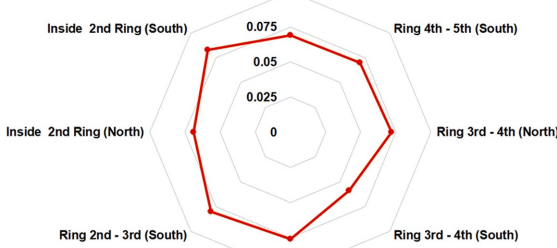

Ring 2nd - 3rd (North)

$2 \mathrm{~km} \_\mathrm{access}$

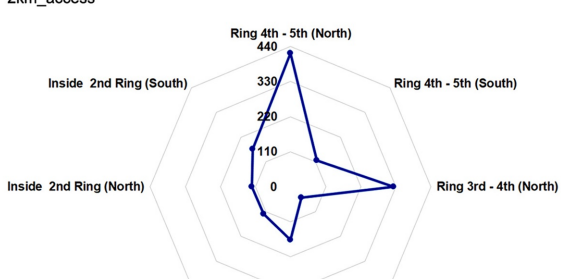

Ring 2nd - 3rd (South)

Ring 3rd - 4th (South)

Figure 6. There are significant north-south differences between rings in the equity of community green space. 


\section{Conclusions and Prospects}

\subsection{Conclusions}

In this study, we developed diverse metrics to assess community green space inequity on a fine scale, which has not been comprehensively studied before, aiming to answer two research questions: (1) how to measure the equity of community green space? (2) how communities vary by green space in Beijing, that is which communities experience inequities regarding these metrics? Through a review of state-of-art green space measures, we calculated a total of 11 metrics from aspects of morphology, visibility, and accessibility, all of which have been proved to have statistically significant associations with residents' health. Measurements of these metrics revealed similar but different geographic variation in green space within the community context in Beijing. Green space morphology presented a monocentric pattern, with communities in Beijing's peripheral areas performing better. In terms of visibility, central areas, especially communities within the 3rd ring road, perform better with greenery in the surrounding streets, which compensates for the lack of green space proportion and complexity. In terms of accessibility, there is a clear north-south difference in all communities.

\subsection{Planning Implications}

From this study we realize that in addition to the commonly used metric of green space rate, other morphological metrics are also inequitable, so urban design cannot simply focus on green space cover, but also other important morphological indicators that have been proven to affect health. In terms of large parks, there are obvious differences between the north and the south in Beijing. It is recommended to build more large parks in the south to ensure the citizens have equal access to large parks.

The findings also suggest several ways in which urban planners and decision makers can bring about more green space justice for residents under the national policy framework. China has launched the renovation project of old communities to make up the shortcomings exposed by COVID-19 control, stating that community development needs to have a green space within $300 \mathrm{~m}$ to ensure that residents have sufficient access to green space. However, no systematic or scientific measures have been proposed to implement this standard so it is impossible to evaluate the design and equity of green space. This study summarized and developed a framework to measure the distribution of green space among communities, that mostly results from the design of the communities, and provides evidence for evaluating the green space and green space renovation in residential areas.

Besides, modern community green spaces are different from the initiatives of 'garden city' movements, gradually developing as strategies for densification, which raised concerns that may encourage property development and result in displacing lower income and marginalized households through gentrification, thereby exacerbating green space inequities. Further analysis can analyze the social factors and development mechanisms behind green space inequality in relation to the socioeconomic attributes of residents.

\subsection{Study Limitations}

These study has a few limitations. First, there are limitations of data availability in terms of visibility and accessibility. In addition to the data used in this study, including green space data, street view images and road networks, for visibility, the street views within some communities are not available due to entrance restrictions, and perception greenness within the communities could not be fully calculated. Second, the experience of greenness may vary depending on the region and personal attributes. Although thresholds of 5-min, 10-min, 15-min walking distances are used in this study, the distance residents are willing to travel around the communities may vary by gender, age, location, and time. Further research can integrate surveys of residents' activities and life patterns in different ranges of life circles, residents' perceived safety, disability of individuals and other environmental factors (e.g., air pollution) in combination. 


\subsection{Future Directions}

There is evidence that green space morphology is related to residents' health, $P M_{2.5}$ concentrations, and the urban heat island effect, but the number of studies is still limited, mainly due to the limitation of data accuracy, which cannot be simulated at a fine scale, and the conclusions obtained are not instructive for urban management and planning. This study has achieved a large-scale, comprehensive and fine-scale green space measurement, which can be combined with other studies in the future to obtain more comprehensive conclusions and better guide the construction and renewal of green space patterns. Also, the measurement of communities can be extended to other spatial units, such as squares, and workplaces, which residents also frequently interact with.

Author Contributions: Conceptualization, Y.Z., Q.W., L.W. and Y.L.; methodology, Y.Z. and Y.L.; formal analysis, Y.Z. and Y.L.; data curation, Y.Z.; writing-original draft preparation, Y.Z. and Y.L.; writing-review and editing, Y.Z., Q.W., L.W. and Y.L.; visualization, Y.Z.; funding acquisition, Y.Z. and Q.W. All authors have read and agreed to the published version of the manuscript.

Funding: This research is supported by Chinese National Postdoctoral Foundation [2019TQ0166].

Conflicts of Interest: The authors declare no conflict of interest.

\section{References}

1. Yang, L.; Ho, J.Y.; Wong, F.K.; Chang, K.K.; Chan, K.L.; Wong, M.S.; Ho, H.C.; Yuen, J.W.; Huang, J.; Siu, J.Y. Neighbourhood green space, perceived stress and sleep quality in an urban population. Urban For. Urban Green. 2020, 54, 126763. [CrossRef]

2. Zhang, Y.; Murray, A.T.; Turner, B.L. Optimizing green space locations to reduce daytime and nighttime urban heat island effects in Phoenix, Arizona. Landsc. Urban Plan. 2017, 165, 162-171. [CrossRef]

3. Kondo, M.C.; Fluehr, J.M.; McKeon, T.; Branas, C.C. Urban green space and its impact on human health. Int. J. Environ. Res. Public Health 2018, 15, 445. [CrossRef]

4. Rugel, E.J.; Brauer, M. Quiet, clean, green, and active: A Navigation Guide systematic review of the impacts of spatially correlated urban exposures on a range of physical health outcomes. Environ. Res. 2020, 185, 109388. [CrossRef] [PubMed]

5. Den Braver, N.; Lakerveld, J.; Rutters, F.; Schoonmade, L.; Brug, J.; Beulens, J. Built environmental characteristics and diabetes: A systematic review and meta-analysis. BMC Med. 2018, 16, 12. [CrossRef]

6. De la Fuente, F.; Saldías, M.A.; Cubillos, C.; Mery, G.; Carvajal, D.; Bowen, M.; Bertoglia, M.P. Green space exposure association with type 2 diabetes mellitus, physical activity, and obesity: A systematic review. Int. J. Environ. Res. Public Health 2021, 18, 97. [CrossRef]

7. Twohig-Bennett, C.; Jones, A. The health benefits of the great outdoors: A systematic review and meta-analysis of greenspace exposure and health outcomes. Environ. Res. 2018, 166, 628-637. [CrossRef]

8. Rigolon, A.; Browning, M.H.E.M.; McAnirlin, O.; Yoon, H. Green space and health equity: A systematic review on the potential of green space to reduce health disparities. Int. J. Environ. Res. Public Health 2021, 18, 2563. [CrossRef] [PubMed]

9. Wang, H.; Tassinary, L.G. Effects of greenspace morphology on mortality at the neighbourhood level: A cross-sectional ecological study. Lancet Planet. Health 2019, 3, e460-e468. [CrossRef]

10. Lachowycz, K.; Jones, A.P. Towards A Better Understanding Of The Relationship Between Greenspace And Health: Development Of A Theoretical Framework. Landsc. Urban Plan. 2013, 118, 62-69. [CrossRef]

11. Shen, Y.; Sun, F; Che, Y. Public green spaces and human wellbeing: Mapping the spatial inequity and mismatching status of public green space in the Central City of Shanghai. Urban For. Urban Green. 2017, 27, 59-68. [CrossRef]

12. Schaeffer, Y.; Tivadar, M. Measuring environmental inequalities: Insights from the residential segregation literature. Ecol. Econ. 2019, 164, 106329. [CrossRef]

13. Comber, A.; Brunsdon, C.; Green, E. Using a GIS-based network analysis to determine urban greenspace accessibility for different ethnic and religious groups. Landsc. Urban Plan. 2008, 86, 103-114. [CrossRef]

14. Chen, W.; Huang, H.; Dong, J.; Zhang, Y.; Tian, Y.; Yang, Z. Social functional mapping of urban green space using remote sensing and social sensing data. ISPRS J. Photogramm. Remote Sens. 2018, 146, 436-452. [CrossRef]

15. Moran, D.; Jones, P.I.; Jordaan, J.A.; Porter, A.E. Does Nature Contact in Prison Improve Well-Being? Mapping Land Cover to Identify the Effect of Greenspace on Self-Harm and Violence in Prisons in England and Wales. In Ann. Am. Assoc. Geogr. 2020, $111,1779-1795$.

16. Kabisch, N.; Haase, D. Green justice or just green? Provision of urban green spaces in Berlin, Germany. Landsc. Urban Plan. 2014, 122, 129-139. [CrossRef]

17. Xu, C.; Haase, D.; Pribadi, D.O.; Pauleit, S. Spatial variation of green space equity and its relation with urban dynamics: A case study in the region of Munich. Ecol. Indic. 2018, 93, 512-523. [CrossRef]

18. Wang, J.; Xu, C.; Pauleit, S.; Kindler, A.; Banzhaf, E. Spatial patterns of urban green infrastructure for equity: A novel exploration. J. Clean. Prod. 2019, 238, 117858. [CrossRef] 
19. Texier, M.L.; Schiel, K.; Caruso, G. The provision of urban green space and its accessibility: Spatial data effects in Brussels. PLoS ONE 2018, 13, e0204684. [CrossRef] [PubMed]

20. Mears, M.; Brindley, P. Measuring urban greenspace distribution equity: The importance of appropriate methodological approaches. ISPRS Int. J. -Geo-Inf. 2019, 8, 286. [CrossRef]

21. You, H. Characterizing the inequalities in urban public green space provision in Shenzhen, China. Habitat Int. 2016, 56, 176-180. [CrossRef]

22. Ode Sang, Å.; Knez, I.; Gunnarsson, B.; Hedblom, M. The effects of naturalness, gender, and age on how urban green space is perceived and used. Urban For. Urban Green. 2016, 18, 268-276. [CrossRef]

23. Sun, P.; Lu, W. Environmental inequity in hilly neighborhood using multi-source data from a health promotion view. Environ. Res. 2022, 204, 111983. [CrossRef]

24. Li, X.; Zhang, C.; Li, W.; Ricard, R.; Meng, Q.; Zhang, W. Assessing street-level urban greenery using Google Street View and a modified green view index. Urban For. Urban Green. 2015, 14, 675-685. [CrossRef]

25. Dony, C.C.; Delmelle, E.M.; Delmelle, E.C. Re-conceptualizing accessibility to parks in multi-modal cities: A Variable-width Floating Catchment Area (VFCA) method. Landsc. Urban Plan. 2015, 143, 90-99. [CrossRef]

26. Wei, F. Greener urbanization? Changing accessibility to parks in China. Landsc. Urban Plan. 2017, 157, 542-552. [CrossRef]

27. Wen, M.; Zhang, X.; Harris, C.D.; Holt, J.B.; Croft, J.B. Spatial disparities in the distribution of parks and green spaces in the USA. Ann. Behav. Med. 2013, 45, S18-S27. [CrossRef] [PubMed]

28. Wu, J.; Chen, H.; Wang, H.; He, Q.; Zhou, K. Will the opening community policy improve the equity of green accessibility and in what ways?-Response based on a 2-step floating catchment area method and genetic algorithm. J. Clean. Prod. 2020, 263, 121454. [CrossRef]

29. Zheng, Z.; Shen, W.; Li, Y.; Qin, Y.; Wang, L. Spatial equity of park green space using KD2SFCA and web map API: A case study of zhengzhou, China. Appl. Geogr. 2020, 123, 102310. [CrossRef]

30. Kronenberg, J.; Haase, A.; Łaszkiewicz, E.; Antal, A.; Baravikova, A.; Biernacka, M.; Dushkova, D.; Filčak, R.; Haase, D.; Ignatieva, M.; et al. Environmental justice in the context of urban green space availability, accessibility, and attractiveness in postsocialist cities. Cities 2020, 106, 102862. [CrossRef]

31. Ekkel, E.D.; de Vries, S. Nearby green space and human health: Evaluating accessibility metrics. Landsc. Urban Plan. 2017, 157, 214-220. [CrossRef]

32. Hamstead, Z.A.; Fisher, D.; Ilieva, R.T.; Wood, S.A.; McPhearson, T.; Kremer, P. Geolocated social media as a rapid indicator of park visitation and equitable park access. Comput. Environ. Urban Syst. 2018, 72, 38-50. [CrossRef]

33. Ibes, D.C. A multi-dimensional classification and equity analysis of an urban park system: A novel methodology and case study application. Landsc. Urban Plan. 2015, 137, 122-137. [CrossRef]

34. Boone, C.G.; Buckley, G.L.; Grove, J.M.; Sister, C. Parks and People: An Environmental Justice Inquiry in Baltimore, Maryland. Ann. Assoc. Am. Geogr. 2009, 99, 767-787. [CrossRef]

35. Tan, P.Y.; Samsudin, R. Effects of spatial scale on assessment of spatial equity of urban park provision. Landsc. Urban Plan. 2017, 158, 139-154. [CrossRef]

36. Venter, Z.S.; Shackleton, C.M.; Van Staden, F.; Selomane, O.; Masterson, V.A. Green Apartheid: Urban green infrastructure remains unequally distributed across income and race geographies in South Africa. Landsc. Urban Plan. 2020, 203, 103889. [CrossRef]

37. Park, K.; Rigolon, A.; Choi, D.a.; Lyons, T.; Brewer, S. Transit to parks: An environmental justice study of transit access to large parks in the US West. Urban For. Urban Green. 2021, 60, 127055. [CrossRef]

38. Wen, C.; Albert, C.; Von Haaren, C. Equality in access to urban green spaces: A case study in Hannover, Germany, with a focus on the elderly population. Urban For. Urban Green. 2020, 55, 126820. [CrossRef]

39. Baró, F.; Camacho, D.A.; Del Pulgar, C.P.; Triguero-Mas, M.; Anguelovski, I. School greening: Right or privilege? Examining urban nature within and around primary schools through an equity lens. Landsc. Urban Plan. 2021, 208, 104019. [CrossRef]

40. Kimpton, A. A spatial analytic approach for classifying greenspace and comparing greenspace social equity. Appl. Geogr. 2017, 82, 129-142. [CrossRef]

41. Li, X.; Huang, Y.; Ma, X. Evaluation of the accessible urban public green space at the community-scale with the consideration of temporal accessibility and quality. Ecol. Indic. 2021, 131, 108231. [CrossRef]

42. Li, Q.; Peng, K.; Cheng, P. Community-Level Urban Green Space Equity Evaluation Based on Spatial Design Network Analysis (sDNA): A Case Study of Central Wuhan, China. Int. J. Environ. Res. Public Health 2021, 18, 10174. [CrossRef] [PubMed]

43. Almohamad, H.; Knaack, A.L.; Habib, B.M. Assessing spatial equity and accessibility of public green spaces in Aleppo City, Syria. Forests 2018, 9, 706. [CrossRef]

44. Seo, S.; Choi, S.; Kim, K.; Kim, S.M.; Park, S.M. Association between urban green space and the risk of cardiovascular disease: A longitudinal study in seven Korean metropolitan areas. Environ. Int. 2019, 125, 51-57. [CrossRef]

45. Schumaker, N.H. Using landscape indices to predict habitat connectivity. Ecology 1996, 77, 1210-1225. [CrossRef]

46. Poortinga, W.; Bird, N.; Hallingberg, B.; Phillips, R.; Williams, D. The role of perceived public and private green space in subjective health and wellbeing during and after the first peak of the COVID-19 outbreak. Landsc. Urban Plan. 2021, 211, 104092. [CrossRef]

47. Williams, T.G.; Logan, T.M.; Zuo, C.T.; Liberman, K.D.; Guikema, S.D. Parks and safety: A comparative study of green space access and inequity in five US cities. Landsc. Urban Plan. 2020, 201, 103841. [CrossRef] 